ORIGINAL ARTICLE

\title{
Continuous Epidural Versus Continuous Spinal Anesthesia for Elderly Patients Undergoing Radical Cystectomy: A Comparative Study
}

\author{
Khaled Hassan Abd Alla*, Moustafa Magdy Nasr*, Lobna Taha El-Dourgham*, Dina A. Salem* \\ * Anesthesia and Surgical intensive care Department, Zagazig University, Egypt.
}

Corresponding Author:

Khaled Hassan Abd Alla

Anesthesia and Surgical intensive care Department, Zagazig University

Khaloda2003@gmail.com

$\begin{array}{ll}\text { Submit Date } & 2019-04-06 \\ \text { Revise Date } & 2019-05-24 \\ \text { Accept Date } & 2019-05-27\end{array}$

ABSTRACT

Background: Bladder cancer is common in geriatrics who have high operative risk and less tolerability to surgical stresses. This study aims at comparing epidural versus continuous spinal anesthesia for elderly patients undergoing radical cystectomy regarding hemodynamics, total volume of bupivacaine used, patient's and surgeon's satisfactions and incidence of complications.

Patient and Methods: Twenty male patients divided into 2 equal groups. Group I received continuous epidural anesthesia, 1-1.5 ml/segment of isobaric bupivacaine $0.5 \%+25 \mu \mathrm{g}$ fentanyl were injected to achieve T4 block then maintenance by $5 \mathrm{ml} / \mathrm{h}$ of isobaric bupivacaine $0.5 \%$ after 2 segment regression. Group II received continuous spinal anesthesia, $7.5 \mathrm{mg}$ hyperbaric bupivacaine $0.5 \%+25 \mu \mathrm{g}$ fentanyl were injected. If T4 block wasn't achieved after 15 minute, $2.5 \mathrm{mg}$ of hyperbaric bupivacaine $0.5 \%$ was given also during surgery $2.5 \mathrm{mg}$ of hyperbaric bupivacaine $0.5 \%$ was given after 2 segment regression to maintain T4 block.

Results: Mean age of both groups was comparable. Heart rate showed a significant decrease at 15 minutes after local anesthetics injection in group II $(69.90 \pm 5.45$ vs $76.70 \pm 4.97)$, while no significant differences were recorded later. Group I showed a statistically significant decrease in MAP in $\mathrm{mmHg}$ at $10 \mathrm{~min}$ (71.93 vs 92.63), at $35 \mathrm{~min}$ (65.07 vs 87.83), at $135 \mathrm{~min}$ (71.47 vs 84.00), and at $255 \mathrm{~min}$ (69.63 vs 80.23). Total dose of bupivacaine was significant smaller in the group II $(44.45 \pm 4.34 \mathrm{mg}$ versus $260.00 \pm 21.08 \mathrm{mg}$ ).

Conclusion: Continuous spinal anesthesia has advantage of more hemodynamic stability with adjustable lower dose of injected local anesthetic and excellent patients' and surgeons' satisfaction.

Keywords: continuous spinal, continuous epidural, cancer bladder, geriatric, radical cystectomy, geriatric, hemodynamics

\section{INTRODUCTION}

B ladder cancer is one of the most common malignancies in the world with an incidence of 330.000 cases per year and a mortality rate of 130.000 cases per year ${ }^{[1]}$.

The choice of primary therapy is therefore strongly influenced by the performance status and age of patients; however radical cystectomy represents the gold standard treatment for invasive bladder cancer ${ }^{[2]}$.
It has been reported that elderly patients who underwent radical cystectomy have a greater risk of perioperative morbidity and mortality due to additional comorbidities, such as cardiac, endocrine, renal, cerebral and respiratory diseases.

Central regional anesthesia (spinal or epidural) potentially may offer physiological advantages not even in elderly patients with coexisting diseases but also in patients with a higher risk associated with general anesthesia, 
as it reduces stress response, the incidence of thromboembolic complications and provides good postoperative analgesia ${ }^{[3]}$. However, because of the high prevalence of medical problems and a reduction in physiologic compensatory mechanisms in these patients, single shot spinal anesthesia usually associated with high risk of severe and prolonged hypotension $^{[3]}$.

Epidural anesthesia has advantage of efficacious postoperative pain control and a reduced rate of cardiac and pulmonary complications. Moreover, the lower rate of postoperative ileus and venous embolism has been reported among these patients due to its sympatholytic effects. Additional potential benefit is relative hypotension which reduces intraoperative blood loss and the need of blood transfusion $^{[4]}$.

In 1907, Continuous spinal anesthesia (CSA) was first described for anesthesia practice and nowadays the technique is used in Europe for more cardiovascular stability in high-risk patients undergoing lower limb and lower abdominal surgery ${ }^{[5]}$. CSA allows titration of small doses of local anesthetic, achieves the appropriate level and duration of anesthesia with minimal hemodynamic changes.

\section{PATIENTS AND METHODS}

After obtaining approval from institutional review board (IRB), this prospective randomized study was carried out at Zagazig University Hospitals, over a 2-years period (from July, 2016 to July, 2018) where Twenty male patients, 65 years of age or older who were scheduled for elective radical cystectomy surgeries were included in this study. All the patients received regional anesthesia during the surgeries either in the form of continuous epidural anesthesia (CEA) or continuous spinal anesthesia (CSA).

Sample Size:

By comparing mean and standard deviation of MAP changes in both techniques in previous study ${ }^{[10]}$ and finding it to be $12.5+0.0$ and $10.0+2.8$ respectively, sample size was calculated by open Epi to be 20 cases (10 cases in each group) with confidence level $95 \%$ and power of the test is $80 \%$.

Study Design: Randomized, Comparative prospective clinical study.

Randomization was done using computer generated number tables and concealed using sealed opaque envelope. Patients and data collector were blind to group assignment. Once enrolled in the study, patients were randomly assigned into 2 equal groups:

- Group I: (10 patients) anesthetized using continuous epidural anesthesia

- Group II: (10 patients) anesthetized using continuous spinal anesthesia.

The current study included patient's consent to the anesthetic procedure, Age > 65 years, ASA II and ASA III and excluded patient's refusal, infection at the injection site, Spinal deformity, neuropathy, any allergy to local anesthetics, coagulopathy and any past history of post spinal headache or migraine.

Routine preoperative assessment was done to all patients by careful history taking, clinical examination and laboratory investigations. Procedure explanation to the patient was done the day before surgery.

Written informed consent was obtained from all participants. The work has been carried out in accordance with The Code of Ethics of the World Medical Association (Declaration of Helsinki) for studies involving humans.

All patients were brought to the preanesthesia room. Standard monitors were placed; pulse oximetry, non-invasive blood pressure cuff and ECG. Sedation with midazolam (1 mg IV) given in 30 second with running $8-10 \mathrm{ml} / \mathrm{kg}$ ringer solution. The patients' vital signs and conscious status were monitored and recorded throughout the procedure.

All blockades were performed through paramedian approach in the L3-L4 or L4-L5 interspace using a 20-gauge epidural catheter through 18 gauge Tuohy needle with the patient sedated in the sitting position.

In group I: The epidural space had been identified by loss of resistance technique to air 
then the epidural catheter was inserted 3-4 cm into the epidural space in cephalic direction. 1$1.5 \mathrm{ml} /$ segment of isobaric bupivacaine $0.5 \%+$ $25 \mu \mathrm{g}$ fentanyl was injected to achieve T4 block (sensory level assessed by pinprick and the quality of motor blockade assessed by Bromage scale) then maintenance $5 \mathrm{ml} / \mathrm{h}$ of isobaric bupivacaine $0.5 \%$ by continuous infusion after 2 segment regression.

In group II: The epidural space had been identified by loss of resistance technique then the epidural needle was pushed a few millimeters forward, until the dura was pierced, this was confirmed by the appearance of CSF. At this moment, the epidural catheter was threaded into the needle as fast as possible, to diminish the loss of CSF. It was inserted 2 to 3 $\mathrm{cm}$ inside the subarachnoid space in cephalic direction. Injection of $7.5 \mathrm{mg}$ hyperbaric bupivacaine $0.5 \%+25 \mu \mathrm{g}$ fentanyl then (sensory level assessed by pinprick and the quality of motor blockade assessed by Bromage scale), if the level didn't reach T4 after 15 minute, $2.5 \mathrm{mg}$ of hyperbaric bupivacaine $0.5 \%$ was given till reach the desired level of $\mathrm{T} 4$ block and during surgery titration of small dose of $2.5 \mathrm{mg}$ hyperbaric bupivacaine $0.5 \%$ was given after 2 segment regression to maintain the desired level of T4 block.

The followings were measured in both groups:

- Hemodynamic changes (BP, $\left.\mathrm{HR}, \mathrm{SpO}_{2} \%\right) \rightarrow$ every 5 minute after initial dose for 15 minute then every 20 minute during the rest of operation.

- Patient satisfaction: At the end of the surgery by verbal rating score (VRS) for satisfaction with analgesia during the operation $(0=$ excellent, $1=$ good, $2=$ fair, $3=$ poor $)^{[6]}$.

- Surgeon satisfaction: At the end of the surgery by Surgeon Satisfaction with Anesthesia Services (SSAS) the scale was composed of four levels (Strongly disagree, Disagree, Agree, strongly agree $)^{[6]}$.

- Total dose of bupivacaine used.

- Incidence of intraoperative and postoperative complications "Patients were followed for one week to detect the emergence of PDPH, backache, infections and any neurological complications").

Study Outcome Measures:

The aim of the current study was to evaluate the safety of continuous spinal anesthesia (CSA) in geriatric patients and comparing it with continuous epidural anesthesia. The primary outcome is the hemodynamic changes while surgeon's and patient's satisfaction was the secondary outcome.

Statistical analysis:

Data was tested for normality using Kolmogrov-Smirnov test and Shapiro-Wilk test. Quantitative data was presented as mean and standard deviation. Qualitative data was presented as number and percentage. Comparisons between the 2 groups for normally distributed numeric variables was done using the Student $\mathrm{t}$ test while for nonnormally distributed numeric variables was done by Mann-Whitney test. Comparisons between the 2 groups of categorical variables was done using Chi square test or fissure exact as appropriate. The probability value ( $\mathrm{p}$-value) $\leq \mathbf{0 . 0 5}$ was considered statistically significant.

\section{RESULTS}

Regarding patient characteristics, there were no differences in demographic characteristics of patients, surgeries' duration, and ASA physical status classification in both groups (Table 1).

Heart rate showed a significant decrease at 15 minutes after local anesthetics injection in group II $(69.90 \pm 5.45$ vs 76.70 \pm 4.97$)$ in compared to group I, while no significant differences were recorded later (Fig. 1). The changes in the oxygen saturation from the baseline were not statistically significant. In addition, the all over differences in oxygen saturation between the two groups were not statistically significant (Fig. 2).

Group I showed a statistically significant decrease in mean BP than in group II at $10 \mathrm{~min}$ (71.93 vs 92.63$)$, at $15 \min (62.83$ vs 91.03$)$ at $35 \mathrm{~min}$ (65.07 vs 87.83 ), at $55 \mathrm{~min}(64.77$ vs $88.33)$, at $75 \mathrm{~min}(72.77 \pm 11.47$ vs $85.73 \pm 5.03)$ at $135 \mathrm{~min}$ (71.47 vs 84.00$)$, at $195 \mathrm{~min}$ (73.17 
vs 83.20$)$, at $255 \mathrm{~min}(69.63$ vs 80.23$)$ and at 335 min (72.03 vs 80.30) (Table 2).

The total dose of bupivacaine was significant smaller in group II than group I $(44.45 \pm 4.34 \mathrm{mg}$ vs $260.00 \pm 21.08 \mathrm{mg}$ ) (Fig. 3). Also the total dose of ephedrine used was significant smaller in group II than group I $(12.35 \pm 2.54 \mathrm{mg}$ vs $34.90 \pm 3.03 \mathrm{mg}$ ) (Table 4), as the number of patient treated of hypotension was lower in group II as compared to group I ( 2 in group II vs 5 in group I) (Table 4).

Regarding patient's satisfaction, group II had excellent and good patients' satisfaction rather group I as $30.0 \%$ of group II patients had excellent satisfaction while no patient in group I expressed excellent satisfaction also $60 \%$ of group II patients expressed good satisfaction while $20.0 \%$ only of group I patients expressed good satisfaction. $80.0 \%$ of group I patients had fair and poor satisfaction while $10 \%$ only of group II patients expressed Fair satisfaction (Table 3).

About surgeon's satisfaction $80.0 \%$ of surgeons' satisfaction toward CSA while $40.0 \%$ of them toward CEA. $60.0 \%$ of surgeons dissatisfied from CEA while $20.0 \%$ only dissatisfied from CSA (Table 3).

Regarding intraoperative complications, the number of patient treated of hypotension is lower in group II as compared to group I (2 vs $5)$. but it was statistically insignificant $(\mathrm{P}>0.05)$, and was managed by $5 \mathrm{mg}$ of ephedrine. Also there were statistically insignificant difference between the two group as regard other complications [high neuroaxial block (1 in group I vs 0 in group II), nausea (4 in group I vs 2 in group II), vomiting ( 3 in group I vs 1 in group II) and shivering (4 in group I vs 5 in group II)]. Nausea and vomiting was managed by correction of hypotension while shivering managed by $25 \mathrm{mg}$ pethidine. (Table 4).

Regarding postoperative complications, no patient in both group complained of post-dural puncture headache. Three patients in the group II and two patients in group I had non-specific backache after the operation. There were no neurological sequelae (motor, sensory or autonomic dysfunction) in any of the patients during the first postoperative week. Also there was no clinical symptoms or signs of infection could be detected in any case (Table 4).

Table (1): Patients characteristics.

\begin{tabular}{|c|c|c|c|c|c|c|c|}
\hline \multicolumn{2}{|c|}{ Variables } & \multicolumn{2}{|c|}{ Group I (CEA) } & \multicolumn{2}{|c|}{ Group II (CSA) } & \multirow[t]{2}{*}{ Test } & \multirow[t]{2}{*}{$P$ value } \\
\hline & & $N$ & $\%$ & $N$ & $\%$ & & \\
\hline \multicolumn{2}{|c|}{ Age } & \multicolumn{2}{|c|}{$67.90 \pm 2.38$} & \multicolumn{2}{|c|}{$67.50 \pm 2.59$} & $0.360 * *$ & 0.723 \\
\hline Sex & Male & 10 & $100.0 \%$ & 10 & $100.0 \%$ & - & - \\
\hline \multirow[t]{2}{*}{ ASA } & II & 8 & $80.0 \%$ & 8 & $80.0 \%$ & $0.001 *$ & 1.00 \\
\hline & III & 2 & $20.0 \%$ & 2 & $20.0 \%$ & & \\
\hline \multicolumn{2}{|c|}{$\begin{array}{l}\text { Average time of } \\
\text { operation } / \mathrm{min}\end{array}$} & \multicolumn{2}{|c|}{$388.0 \pm 93.67$} & \multicolumn{2}{|c|}{$387.00 \pm 36.53$} & $-0.038 * *$ & 0.970 \\
\hline
\end{tabular}

*Chi square test.

**Mann Whitney test.

$\mathrm{CEA}=$ Continuous Epidural Anesthesia.

CSA = Continuous Spinal Anesthesia.

The data of age and average time of operation expressed as mean \pm SD,

The data of sex and ASA expressed as number and percentage.

$P$ value $<0.05$ was considered statistically significant otherwise it was insignificant. 
Table (2): Changes in Mean Blood Pressure ( $\mathrm{mmHg}$ ) in both groups.

\begin{tabular}{|c|c|c|c|c|}
\hline \multirow[t]{2}{*}{ Time } & Group I (CEA) & Group II (CSA) & \multirow[t]{2}{*}{ Test** } & \multirow[t]{2}{*}{ P value } \\
\hline & Mean $\pm S D$ & Mean $\pm S D$ & & \\
\hline $5 \mathrm{~min}$ & $87.37 \pm 9.47$ & $93.83 \pm 8.00$ & -1.627 & 0.104 \\
\hline $10 \mathrm{~min}$ & $71.93 \pm 8.69 *$ & $92.63 \pm 7.44$ & -3.631 & $<0.001$ \\
\hline $15 \mathrm{~min}$ & $62.83 \pm 11.64 *$ & $91.03 \pm 8.75$ & -3.782 & $<0.001$ \\
\hline $35 \mathrm{~min}$ & $65.07 \pm 15.17 *$ & $87.83 \pm 9.31$ & -3.102 & 0.002 \\
\hline $55 \mathrm{~min}$ & $64.77 \pm 10.88 *$ & $88.33 \pm 10.10$ & -3.250 & 0.001 \\
\hline $75 \mathrm{~min}$ & $72.77 \pm 11.47 *$ & $85.73 \pm 5.03$ & -2.913 & 0.004 \\
\hline $95 \mathrm{~min}$ & $73.43 \pm 10.90$ & $87.17 \pm 16.90$ & -1.928 & 0.054 \\
\hline $115 \mathrm{~min}$ & $77.90 \pm 9.68$ & $82.50 \pm 8.44$ & -0.832 & 0.405 \\
\hline $135 \mathrm{~min}$ & $71.47 \pm 11.86^{*}$ & $84.00 \pm 9.21$ & -2.156 & 0.031 \\
\hline 155min & $78.87 \pm 11.0$ & $78.87 \pm 13.95$ & -0.416 & 0.677 \\
\hline $175 \mathrm{~min}$ & $77.23 \pm 12.66$ & $78.83 \pm 8.43$ & -0.189 & 0.850 \\
\hline $195 \mathrm{~min}$ & $73.17 \pm 10.64 *$ & $83.20 \pm 7.30$ & -2.193 & 0.028 \\
\hline $215 \mathrm{~min}$ & $79.77 \pm 11.54$ & $78.07 \pm 8.54$ & -0.756 & 0.450 \\
\hline $235 \mathrm{~min}$ & $76.03 \pm 15.44$ & $80.73 \pm 9.87$ & -0.492 & 0.623 \\
\hline $255 \mathrm{~min}$ & $69.63 \pm 9.10 *$ & $80.23 \pm 9.80$ & -2.120 & 0.034 \\
\hline $275 \mathrm{~min}$ & $75.73 \pm 10.98$ & $79.37 \pm 15.30$ & -1.058 & 0.290 \\
\hline $295 \mathrm{~min}$ & $74.73 \pm 13.17$ & $83.00 \pm 7.91$ & -1.816 & 0.069 \\
\hline $315 \mathrm{~min}$ & $72.87 \pm 11.58$ & $77.37 \pm 13.24$ & -0.832 & 0.406 \\
\hline 335 min & $72.03 \pm 9.15 *$ & $80.30 \pm 8.72$ & -1.968 & 0.049 \\
\hline $355 \mathrm{~min}$ & $73.00 \pm 26.92$ & $67.80 \pm 36.54$ & -0.455 & 0.649 \\
\hline 375 min & $62.70 \pm 33.36$ & $60.80 \pm 42.70$ & -0.914 & 0.361 \\
\hline $395 \mathrm{~min}$ & $36.13 \pm 38.31$ & $42.13 \pm 44.87$ & -0.767 & 0.443 \\
\hline 415 min & $22.47 \pm 36.26$ & $25.43 \pm 40.96$ & -0.419 & 0.675 \\
\hline 435 min & $69.57 \pm 34.93$ & $70.53 \pm 37.28$ & -0.870 & 0.502 \\
\hline
\end{tabular}

* Significant lower.

* Mann Whitney test.

CEA = Continuous Epidural Anesthesia.

$\mathrm{CSA}=$ Continuous Spinal Anesthesia.

25 The data are expressed as mean $\pm \mathrm{SD}$.

25 $\mathrm{P}$ value $<0.05$ was considered statistically significant otherwise it was insignificant. 
Table (3): Patient's and surgeon's satisfaction in both group.

\begin{tabular}{|c|c|c|c|c|c|c|c|}
\hline \multirow{2}{*}{\multicolumn{2}{|c|}{ Satisfaction }} & \multicolumn{2}{|c|}{$\begin{array}{c}\text { Group I } \\
\text { (CEA) }\end{array}$} & \multicolumn{2}{|c|}{$\begin{array}{l}\text { Group II } \\
\text { (CSA) }\end{array}$} & \multirow[t]{2}{*}{ Test** } & \multirow[t]{2}{*}{$P$ value } \\
\hline & & $N$ & $\%$ & $N$ & $\%$ & & \\
\hline \multirow{4}{*}{$\begin{array}{c}\text { Patient } \\
\text { Satisfaction }\end{array}$} & $O($ Excellent $)$ & 0 & $0.0 \%$ & $3 *$ & $30.0 \%$ & \multirow[t]{4}{*}{9.578} & \multirow[t]{4}{*}{0.017} \\
\hline & 1 (Good) & 2 & $20.0 \%$ & $6^{*}$ & $60.0 \%$ & & \\
\hline & 2 (Fair) & $5^{*}$ & $50.0 \%$ & 1 & $10.0 \%$ & & \\
\hline & 3 (Poor) & $3^{*}$ & $30.0 \%$ & 0 & $0.0 \%$ & & \\
\hline \multirow{4}{*}{$\begin{array}{c}\text { Surgeon } \\
\text { Satisfaction }\end{array}$} & Strongly agree & 0 & $0.0 \%$ & $4 *$ & $40.0 \%$ & \multirow[t]{4}{*}{11.329} & \multirow[t]{4}{*}{0.002} \\
\hline & Agree & 4 & $40.0 \%$ & 4 & $40.0 \%$ & & \\
\hline & Disagree & 3 & $30.0 \%$ & 1 & $10.0 \%$ & & \\
\hline & Strongly disagree & 3 & $30.0 \%$ & 1 & $10.0 \%$ & & \\
\hline
\end{tabular}

\section{* Significant higher}

Ls ** Chi square test

25. CEA $=$ Continuous Epidural Anesthesia.

25 CSA $=$ Continuous Spinal Anesthesia.

Ls The data are expressed as number and percentage

25 $\mathrm{P}$ value $<0.05$ was considered statistically significant otherwise it was insignificant.

Table (4): Complications and total dose of ephedrine used/mg.

\begin{tabular}{|c|c|c|c|c|c|c|}
\hline & \multicolumn{2}{|c|}{$\begin{array}{c}\text { Group I } \\
\text { (CEA) }\end{array}$} & \multicolumn{2}{|c|}{$\begin{array}{c}\text { Group II } \\
\text { (CSA) }\end{array}$} & \multirow[t]{2}{*}{ Test } & \multirow[t]{2}{*}{$P$ value } \\
\hline & $\mathrm{N}$ & $\%$ & $\mathrm{~N}$ & $\%$ & & \\
\hline High neuraxial block & 1 & $10 \%$ & 0 & $0.0 \%$ & $0.99 * *$ & 1.00 \\
\hline Nausea & 4 & $40 \%$ & 2 & $20 \%$ & $0.867 * *$ & 0.628 \\
\hline Vomiting & 3 & $30 \%$ & 1 & $10 \%$ & $0.896^{* *}$ & 0.582 \\
\hline Shivering & 4 & $40 \%$ & 5 & $50 \%$ & $0.968 * *$ & 1.00 \\
\hline Backache & 2 & $20 \%$ & 3 & $30 \%$ & $0.968 * *$ & 0.98 \\
\hline Post dural puncture headache & 0 & - & 0 & - & - & - \\
\hline Infection & 0 & - & 0 & - & - & - \\
\hline Neurological complication & 0 & - & 0 & - & - & - \\
\hline $\begin{array}{l}\text { Intraoperative hypotension } \\
\text { (no. of treated patients) }\end{array}$ & 5 & $50 \%$ & 2 & $20 \%$ & $0.672 * *$ & 0.349 \\
\hline Total dose of ephedrine used $/ \mathrm{mg}$ & \multicolumn{2}{|c|}{ Mean $\pm S D$} & \multicolumn{2}{|c|}{ Mean $\pm S D$} & $-3.829 * * *$ & $<0.001$ \\
\hline
\end{tabular}

* Significant lower

** Chi square test

*** Mann Whitney test

$\mathrm{CEA}=$ Continuous Epidural Anesthesia.

$\mathrm{CSA}=$ Continuous Spinal Anesthesia.

The data are expressed as number and percentage except dose of ephedrine expressed as mean \pm SD.

$\mathrm{P}$ value $<0.05$ was considered statistically significant otherwise it was insignificant. 


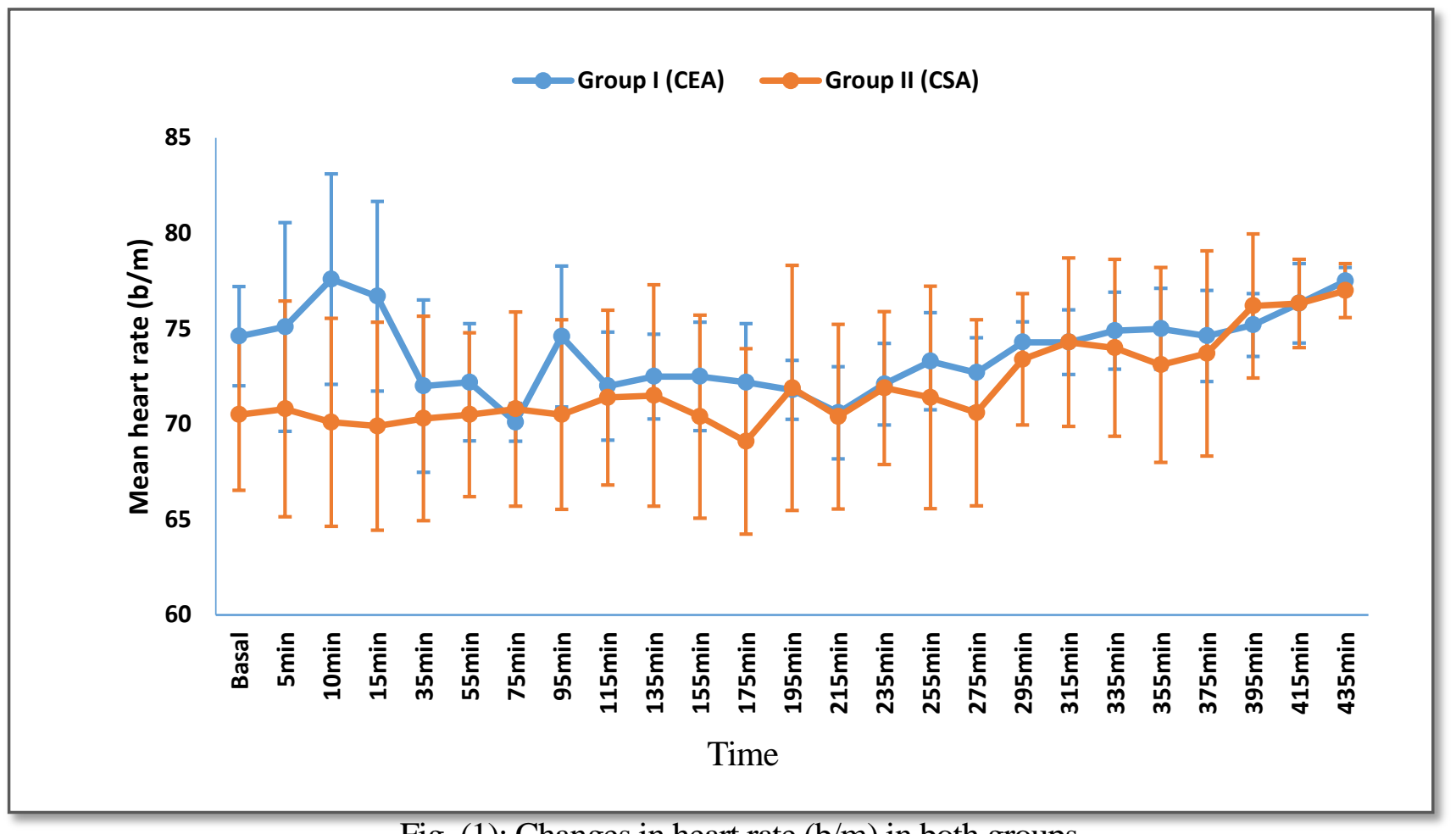

Fig. (1): Changes in heart rate $(\mathrm{b} / \mathrm{m})$ in both groups.

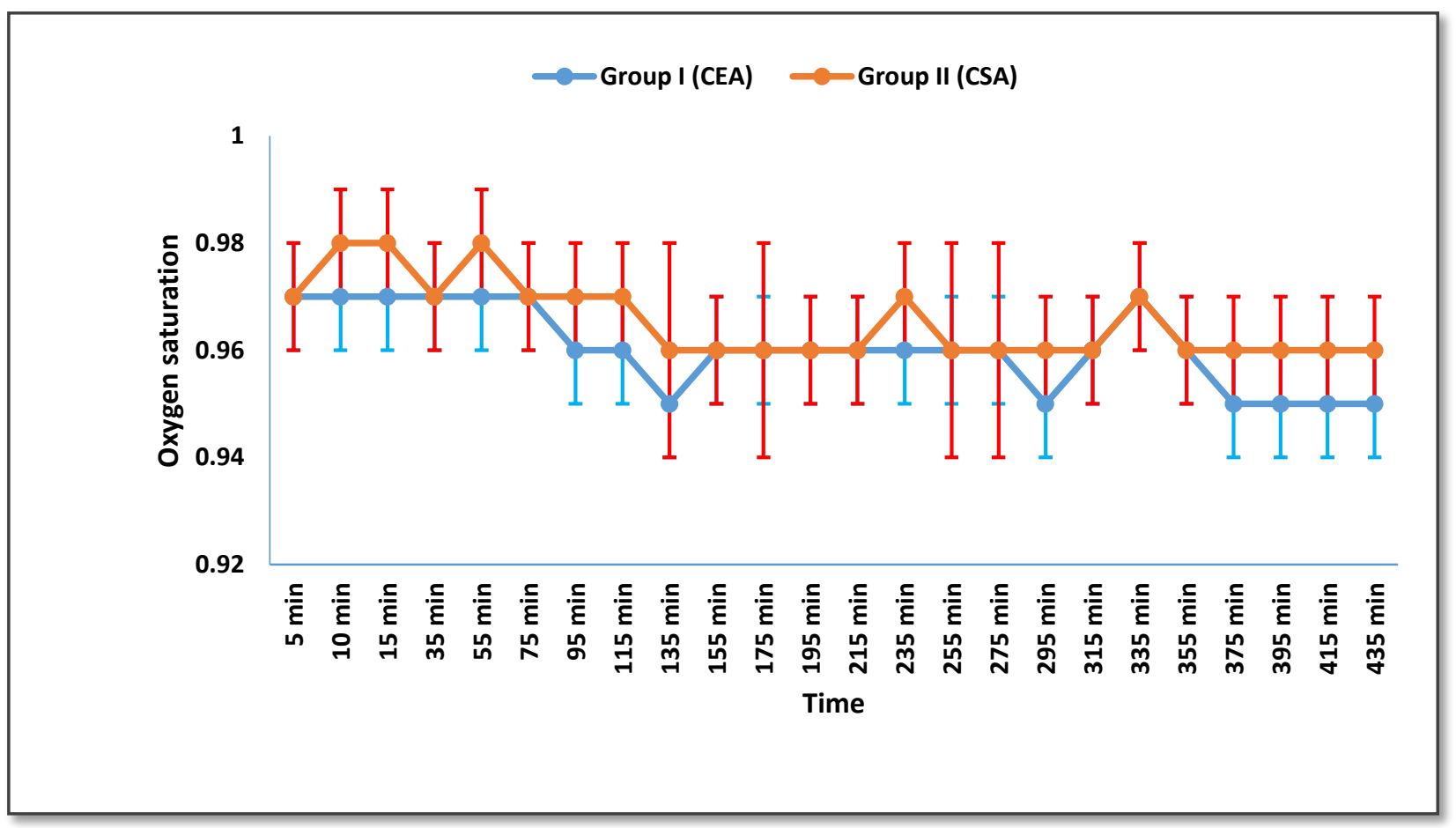

Fig. (2): Changes in Oxygen Saturation (\%) in both groups. 


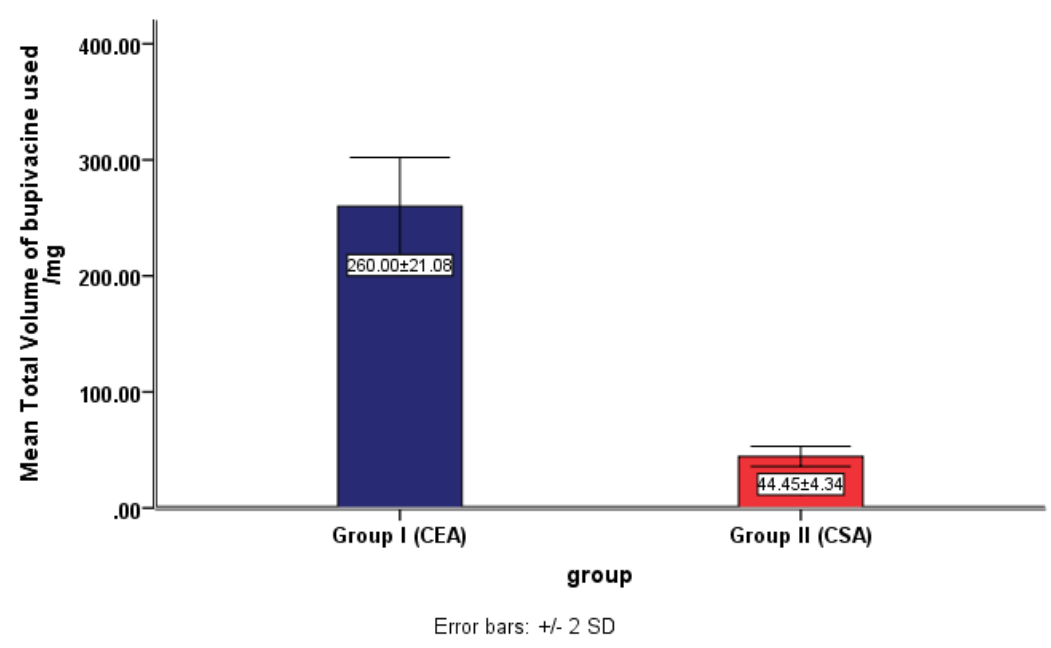

Fig. (3): Total dose of bupivacaine used (mg) in both groups.

\section{DISCUSSION}

In the current study, we compared the hemodynamic changes, total injected dose of bupivacaine and ephedrine used, patient's and surgeon's satisfaction and incidence of complications between the continuous epidural anesthesia group and continuous spinal anesthesia group in geriatric patients undergoing radical cystectomy.

As regard to hemodynamics the current study showed no statistically significant differences were found among the two groups with respect to baseline mean arterial pressure (MAP) values. While patients in the CEA group showed a statistically significant decrease in BP when the two groups were compared to each other. These results could be explained by in continuous spinal anesthesia we used lower dose of bupivacaine at induction of anesthesia and titration of small doses of bupivacaine to maintain the anesthesia.

This finding was in accordance with Zhi et al. ${ }^{[7]}$ who concluded that CSA is a useful anesthetic technique using small titrated doses provide better hemodynamic stability than single shot anesthesia (SSA) and CEA in elderly patients.

Imbelloni et al. ${ }^{[8]}$ also found that continuous spinal anesthesia was hemodynamically more stable than combined spinal epidural anesthesia in a study on 240 patients who were scheduled for lower limb orthopedic surgery, they compared continuous spinal anesthesia and combined spinal epidural anesthesia and their results were 17 patients had hypotension in combined spinal epidural anesthesia and 4 patients in continuous spinal anesthesia.

Reisli et al. ${ }^{[9]}$ compared continuous spinal anesthesia and epidural anesthesia using prilocaine on 30 old patients underwent TURP. They found in epidural group patient developed significant decrease in mean arterial blood pressure more than the continuous spinal anesthesia group, which was in accordance with our results.

As regards total dose of bupivacaine used in both groups, the current study showed that bupivacaine doses in the continuous epidural group were significantly higher than those in the continuous spinal anesthesia group $(260.00 \pm 21.08 \mathrm{mg}$ in group I versus $44.45 \pm 4.34$ $\mathrm{mg}$ in group II), Epidural doses are much higher than spinal doses most probably due to compensation for the uptake by extraneural tissues (in particular epidural fat) and for the uptake by systemic absorption. Such higher doses of bupivacaine in epidural anesthesia increased the risk of systemic toxicity either due to unintentional intravascular injection or due to systemic absorption of bupivacaine. This finding was in accordance with Reeham et al ${ }^{[10]}$ who showed that total intraoperative bupivacaine dose was 
significantly lower in CSA group as compared to group CEA $(11.7 \pm 2.4$ vs. $83.3 \pm 29.4 \mathrm{mg}$; $\mathrm{P}$ $<0.001)$ in a comparative study of continuous Spinal anesthesia with continuous epidural anesthesia in elderly patients undergoing transurethral resection of prostate (TURP).

In a prospective study, White et al. ${ }^{[11]}$ showed a significant correlation between hypotension, mortality and dose of intrathecal local anesthesia. That study recommended that the dose of intrathecal LA should be decreased to the lowest possible, which may potentially reduce mortality for high-risk and elderly patients. They concluded that intrathecal dose of bupivacaine $0.5 \%$ should be reduced towards $1.5 \mathrm{ml}$. This was in accordance with our results which supported the use of lower dose of local anesthesia, especially in fragile, elderly patient.

As regard to total dose of ephedrine used the study showed that it was significantly smaller in the CSA group than in the CEA group $(12.35 \pm 2.54 \mathrm{mg}$ in group II versus $34.90 \pm 3.03$ $\mathrm{mg}$ in group I) and this reflected the more frequent episodes of hypotension in CEA group than CSA group and the more hemodynamic stability in CSA group. This finding was in accordance with Rabab and Shahira ${ }^{[12]}$ study in a comparative study of continuous Spinal anesthesia with continuous epidural anesthesia in Thirty elderly male patients (above 70 years) scheduled for surgical repair of hip fracture, they demonstrated that CSA with fentanyl provided fewer episodes of hypotension and no severe hypotension in these elderly high risk patients.

Reeham et al. [10] showed that Total ephedrine dose was significantly lower in CSA group as compared to group CEA in a comparative study in elderly patients undergoing transurethral resection of prostate (TURP), which was in accordance with our results.

Concerning to patient's and surgeon's satisfaction the current study showed that CSA group had excellent and good patient's satisfaction rather than CEA group as $30.0 \%$ of CSA patients had excellent satisfaction while no patient in CEA group expressed excellent satisfaction also $60 \%$ of CSA patients expressed good satisfaction while $20.0 \%$ only of CEA patients expressed good satisfaction. $80.0 \%$ of CEA patients had fair and poor satisfaction while $10 \%$ only of CSA patients expressed Fair satisfaction. About surgeon's satisfaction $80.0 \%$ of surgeon's satisfaction toward CSA while $40.0 \%$ of them toward CEA. $60.0 \%$ of surgeons dissatisfied from CEA while $20.0 \%$ only dissatisfied from CSA.

This result was in accordance with Sabry and Sameh $^{[13]}$ who's showed that $87.5 \%$ of patients had excellent satisfaction and $95 \%$ of surgeons was strongly agree toward CSA in a study carried out on Forty adult patients scheduled for lower abdominal surgeries.

As regard to intra-operatve complications the number of patients treated of hypotension (decrease in mean arterial blood pressure by $20 \%$ or more from baseline or systolic blood pressure less than $90 \mathrm{mmHg}$ ) intraoperative was lower in CSA group as compared to CEA group (2 vs 5). as regard to other intraoperative complication there were statistically insignificant difference between CEA as compared to CSA [high neuroaxial block (1 vs 0 ), nausea (4 vs 2), vomiting (3 vs 1 ) and shivering (4 vs 5)].

Concerning post-operative complications, no patient in both groups complained of post-dural puncture headache. Three patients in the CSA group and two patients in the CEA group had non-specific backache after the operation. The backaches occurred in the lumbosacral area and lasted 3-5 days, all the patients described the backaches as mild. There were no clinical symptoms or signs of infection could be detected in any case. Also There were no neurological sequelae (motor, sensory or autonomic dysfunction) in any of the patients during the first postoperative week.

This result was in accordance with $\mathrm{Lux}^{[5]}$ who concluded that continuous spinal anesthesia appears to be a safe and appropriate anesthetic technique in lower leg surgery for aged patients. Also was in accordance with Imbelloni et al. ${ }^{[8]}$ whose found that, CSA 
provided good surgical conditions with low incidence of complications.

Finally, Radical cystectomy in strict regional anesthesia was feasible and could be offered particularly to geriatric patients. Continuous spinal anesthesia was a good alternative technique as well as continuous epidural anesthesia. It provides a good anesthetic profile using smaller anesthetic dose with minimal hemodynamic changes and although few side effects were found yet the small sample size is not reliable concerning neurological complications.

\section{CONCLUSION}

Continuous spinal anesthesia (CSA) is an effective safe technique using small titrating dose of local anesthetic allowing better control of sensory and motor block level, decreasing the risk of local anesthetic toxicity and provides better hemodynamic stability with fewer episodes of hypotension with no severe hypotension which can used as alternative to continuous epidural anesthesia (CEA) in elderly patients.

\section{Declaration of interest}

The authors report no conflicts of interest. The authors alone are responsible for the content and writing of the paper.

Funding information None declared

\section{REFERENCES}

[1] Ploeg M, Aben KK and Kiemeney LA: The present and future burden of urinary bladder cancer in the world. World J Urol 2009; 27: 289-293.

[2] Stenzl A, Cowan NC, De Santis M, Kuczyk MA, Merseburger AS, Ribal MJ et al.: Treatment of muscle-invasive and metastatic bladder cancer: update of the EAU guidelines. Eur Urol 2011; 59: 1009-1018

[3] Karl A, Schneevoigt B., Weninger E, Grimm and Stief C: Feasibility of radical cystectomy in exclusive spinal and/or epidural anaesthesia. World J Urol 2013; 31: 1279-1284.
[4] Kettner SC, Willschke $\mathrm{H}$ and Ma rhofer P: Does regional anaesthesia really improve outcome?. Br J Anaesth 2011; 107(1):90-95.

[5] Lux EA: Continuous spinal anesthesia for lower limb surgery: A retrospective analysis of 1212 cases. Local Reg Anesth 2012; 5: 63-67.

[6] Ahmed AM, Elham M, Khalid M and Islam M: Scoring Systems in Anesthesia, Nature and Science 2016; 14(4).

[7] Zhi YB, Phui SAY, Siyu L, Sneha EE, Chee SY, Kwee LW et al.: Continuous spinal anaesthesia: A retrospective analysis of 318 cases. Indian J Anaesth 2018; 62:765-72.

[8] Imbelloni1 LE, Gouveia MA and Cordeiro JA: Continuous spinal anesthesia versus combined spinal epidural block for major orthopedic surgery, prospective randomized study. Sao Paulo Med J. 2009; 127(1):7-11.

[9] Reisli R, Celik J, Tuncer S and Yosunkaya A.: Anesthetic and hemodynamic effects of continuous spinal versus continuous epidural anesthesia with prilocaine. European Journal of Anesthesiology 2003; 20 (1): 26-30.

[10] Reeham SE, Mohamed ZA, Hanan FK, Mohamed AM and Yasser MS: Comparative study between continuous epidural anaesthesia and continuous Wiley Spinal ${ }^{\circledR}$ anaesthesia in elderly patients undergoing TURP. Egyptian Journal of Anaesthesia 2016; 32: 527-533.

[11] White SM, Moppett IK, Griffiths R, Johansen A, Wakeman $\mathrm{R}$ and Boulton C: Secondary analysis of outcomes after 11,085 hip fracture operations from the prospective UK anaesthesia sprint audit of practice (ASAP.2). Anaesthesia 2016; 71: 506-514.

[12] Rabab S and Shahira EM: Continuous spinal anesthesia versus single small dose bupivacaine-fentanyl spinal anesthesia in high risk elderly patients: A randomized controlled trial. Egyptian Journal of Anaesthesia 2015; 31: 233-238.

[13] Sabry MA and Sameh FS: Continuous spinal anesthesia for elderly patients with cardiomyopathy undergoing lower abdominal surgeries. Egyptian Journal of Anaesthesia 2009; 32: 535-540.

To Cite This Article: Abd Alla $\mathrm{KH}^{*}$, Nasr MM*, El-Dourgham LT*, Salem DA, Continuous Epidural Versus Continuous Spinal Anesthesia for Elderly Patients Undergoing Radical Cystectomy: A Comparative Study, ZUMJ 2020; 26 (2):313-322 Doi: 10.21608/zumj.2019.11498.1193 